\title{
Treatment with near-infrared radiation promotes apoptosis in pancreatic cancer cells
}

\author{
TOMOHIKO OBAYASHI ${ }^{1}$, KOHEI FUNASAKA ${ }^{1}$, EIZABURO OHNO ${ }^{1}$, RYOJI MIYAHARA ${ }^{1}$, \\ YOSHIKI HIROOKA ${ }^{1}$, MICHINARI HAMAGUCHI ${ }^{2}$, HIDEMI GOTO ${ }^{1}$ and TAKESHI SENGA ${ }^{2}$ \\ ${ }^{1}$ Department of Gastroenterology and Hepatology; ${ }^{2}$ Division of Cancer Biology, \\ Nagoya University Graduate School of Medicine, Nagoya, Aichi 466-8550, Japan
}

Received August 2, 2014; Accepted April 20, 2015

DOI: $10.3892 / 01.2015 .3399$

\begin{abstract}
Cancer remains one of the leading causes of human mortality worldwide. Radiation and chemotherapy are commonly used for cancer treatment; however, the combination of these therapies and surgery do not completely eradicate cancer cells. Near-infrared radiation (NIR) is a low-energy form of radiation that exerts multiple effects on mammalian cells. Previous studies have reported that NIR induces DNA double-strand breaks and apoptosis of cancer cells. In the present study, a 915-nm laser was used to examine the effects of NIR on pancreatic cancer cells. Irradiation of pancreatic cancer cells using a 915-nm laser significantly induced caspase- 3 activation and apoptosis. In addition, the combination of gemcitabine treatment and a 915-nm laser synergistically increased the number of apoptotic cells. The results of the present study indicate the use of infrared irradiation and chemotherapy may be a possible therapy for the treatment of cancer.
\end{abstract}

\section{Introduction}

Although considerable knowledge of cancer biology has been acquired over the last few decades, cancer remains one of the major causes of mortality worldwide. Surgical resection is the most effective treatment; however, in the majority of cases, the tumor cells have already advanced locally or metastasized to distant organs by the time of diagnosis. Chemotherapy, a commonly used treatment for cancers that may not be

Correspondence to: Professor Takeshi Senga, Division of Cancer Biology, Nagoya Universtiy Graduate School of Medicine, 65 Tsurumai, Nagoya, Aichi 466-8550, Japan

E-mail: tsenga@med.nagoya-u.ac.jp

Professor Hidemi Goto, Department of Gastroenterology and Hepatology, Nagoya University Graduate School of Medicine, Nagoya, Aichi 466-8550, Japan

E-mail: hgoto@med.nagoya-u.ac.jp

Key words: near-infrared radiation, apoptosis, gemcitabine, caspase-3, pancreatic cancer removed by surgery, often results in severe side-effects due to the delivery of drugs to normal cells (1). As a result of these side-effects, the high doses of chemotherapy required to completely eradicate cancer cells are not tolerated in humans. In addition, the majority of cancer cells eventually acquire drug resistance and result in mortality. Therefore, the development of additional drugs or novel methods for the treatment of cancer is urgently required.

Radiation therapy is a highly targeted and effective way to treat certain types of cancer with limited metastasis (2). This treatment uses high-energy radiation, such as X-rays, $\gamma$-rays and charged particles. High-energy radiation induces double strand breaks in DNA, which promotes apoptosis of cancer cells (3). However, the radiation also results in severe damage to normal cells. Therefore, irradiation must be limited to the cancerous area to minimize the side-effects of this treatment. In contrast to these high-energy radiations, less energetic forms of radiation have not yet been fully evaluated for their anti-cancer functions. Near-infrared radiation (NIR) is a shorter wavelength of radiation in the infrared region of the spectrum, ranging between 750 and 2,500 $\mathrm{nm}$. It has previously been reported that irradiation in the near-infrared region has multiple effects on cells. NIR induces the proliferation of keratinocytes (4), promotes cell attachment (5), attenuates the infarct size following myocardial infarction in rats and dogs $(6,7)$ and regenerates and induces the proliferation of skeletal muscle (8). In addition, NIR has been demonstrated to have an inhibitory effect on advanced neoplasia (9). Broad-spectrum irradiation ranging between 1,100 and 1,800 $\mathrm{nm}$ resulted in apoptosis in multiple cancer cell types in vitro, independent of thermal energy (10). These previous studies have indicated that NIR may be useful for cancer treatment; however, additional studies are required to further confirm the effects of NIR on cancer cells. In the present study, a 915-nm laser was used to investigate the effects of NIR on pancreatic cancer cells.

\section{Materials and methods}

Near-infrared device and irradiation. KP4 and MIA-PaCa2 cells (Japanese Collection of Research Bioresources Cell Bank, Osaka, Japan) were cultured with media in 96 -well plates and incubated at $25^{\circ} \mathrm{C}$ prior to irradiation. The cells were irradiated with a gallium arsenide-based 
A
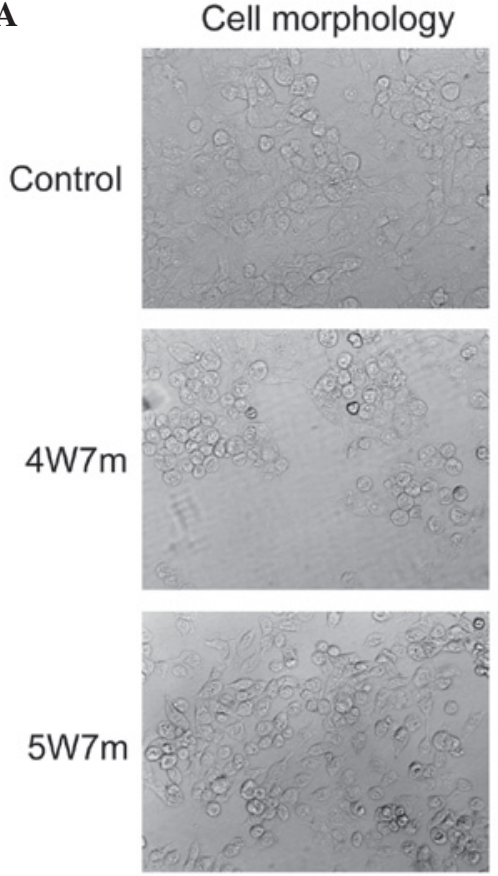

B

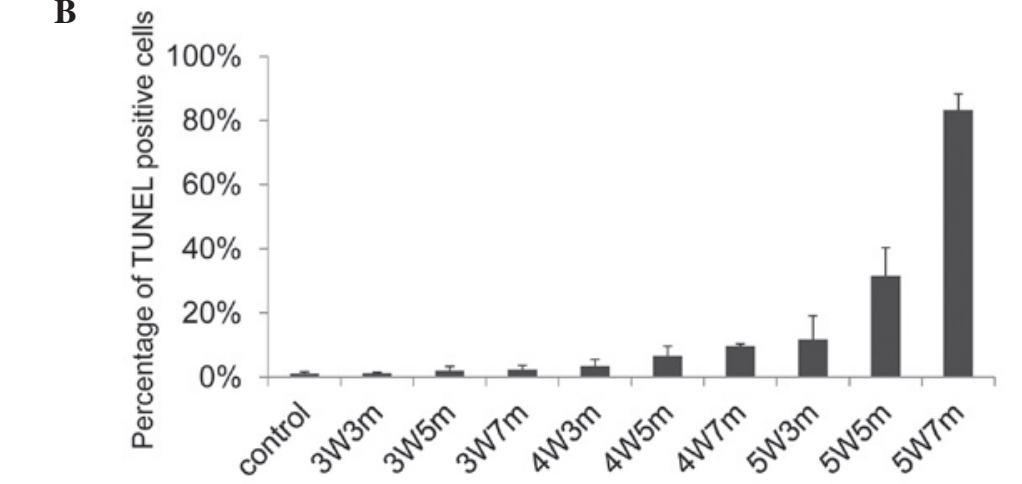

TUNEL
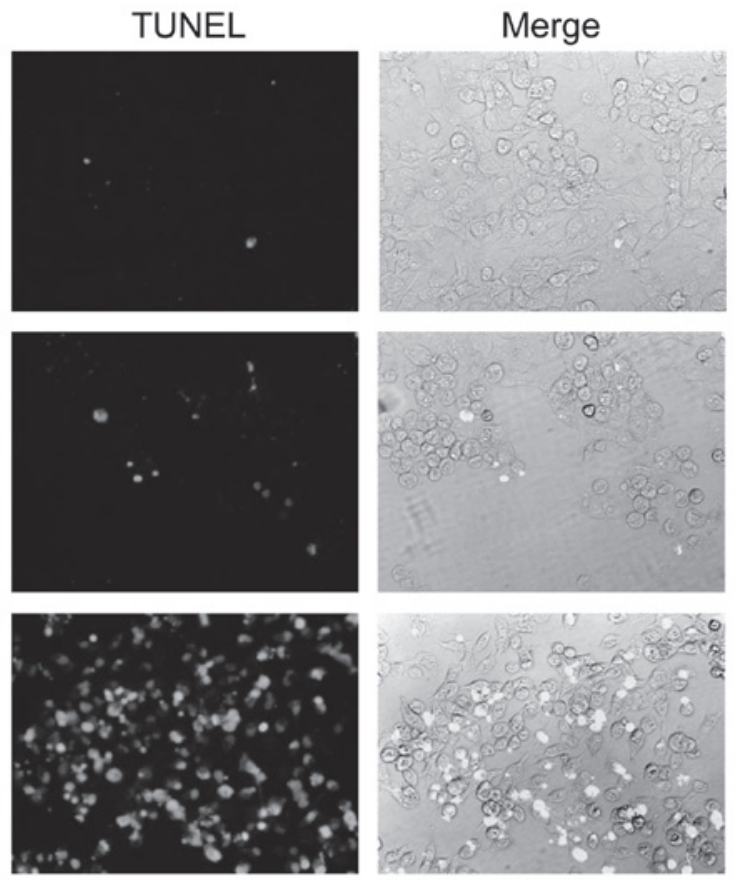

Figure 1. Near-infrared irradiation promotes apoptosis of KP4 cells. (A) KP4 cells cultured in 96-well plates were irradiated with a $915 \mathrm{~nm}$ laser at different powers and for various durations; $24 \mathrm{~h}$ later, the cells were subjected to the TUNEL assay to detect apoptotic cells. Representative pictures of the TUNEL assay are presented. (B) TUNEL positive cells were counted, and the graph indicates the percentage of TUNEL positive cells. A total of 5 independent fields were selected for evaluation, and 3 independent experiments were performed. $3 \mathrm{~W} 3 \mathrm{~m}$, cells treated with a 3 -Watt laser for 3 min; $3 \mathrm{~W} 5 \mathrm{~m}$, cells treated with a 3-Watt laser for $5 \mathrm{~min} ; 3 \mathrm{~W} 7 \mathrm{~m}$, cells treated with a 3-Watt laser for $7 \mathrm{~min} ; 4 \mathrm{~W} 3 \mathrm{~m}$, cells treated with a 4-Watt laser for $3 \mathrm{~min}$; 4W5m, cells treated with a 4-Watt laser for $5 \mathrm{~min} ; 4 \mathrm{~W} 7 \mathrm{~m}$, cells treated with a 4-Watt laser for $7 \mathrm{~min} ; 5 \mathrm{~W} 3 \mathrm{~m}$, cells treated with a 5-Watt laser for $3 \mathrm{~min} ; 5 \mathrm{~W} 5 \mathrm{~m}$, cells treated with a 5 -Watt laser for $5 \mathrm{~min} ; 5 \mathrm{~W} 7 \mathrm{~m}$, cells treated with a 5 -Watt laser for $7 \mathrm{~min}$. $\mathrm{P}<0.05$ between control and $4 \mathrm{~W} 7 \mathrm{~m}$ or $5 \mathrm{~W} 7 \mathrm{~m}$.

laser (Brother Industries, Nagoya, Japan) with a wavelength of $915 \mathrm{~nm}$ at different powers and for varying durations, as indicated in Fig. 1.

Cells. KP4 and MIA-PaCa2 cells were maintained in Dulbecco's modified Eagle's medium (Wako Pure Chemical Industries, Ltd., Osaka, Japan), and PK9 cells were maintained in RPMI (Wako Pure Chemical Industries, Ltd.) supplemented with $10 \%$ FBS (Equitech-Bio, Inc., Kerrville, TX, USA).

TUNEL assay. The cells were irradiated using the $915 \mathrm{~nm}$ laser, and 24 h post-irradiation, the cells were fixed with $4 \%$ paraformaldehyde (Wako Pure Chemical Industries, Ltd.) and subjected to the TUNEL assay using the in situ Cell Death Detection kit (Roche Diagnostics, Basel Switzerland) and fluorescein according to the manufacturer's protocol. Cells in five randomly selected fields were evaluated, and three independent experiments were performed. Images were captured using a BX60 fluorescence microscopy (Olympus, Tokyo, Japan) at 100X magnification.

Caspase-3 assay. The cells were irradiated using a $915 \mathrm{~nm}$ laser, and $2 \mathrm{~h}$ post-irradiation, the cells were fixed with $4 \%$ paraformaldehyde and subjected to the caspase-3 assay using the NucView 488 Caspase-3 Assay kit for Live Cells (Biotium, Inc., Hayward, CA, USA). Cells in five randomly selected fields were evaluated, and three independent experiments were performed. Images were captured using a BX60 fluorescence microscopy (Olympus, Tokyo, Japan) at 100X magnification.

Temperature measurement. The temperature of the media during irradiation was measured using a thermocouple (Brother Industries).

Statistical analysis. Data are expressed as the mean \pm standard deviation. Comparisons between the groups were performed 
A
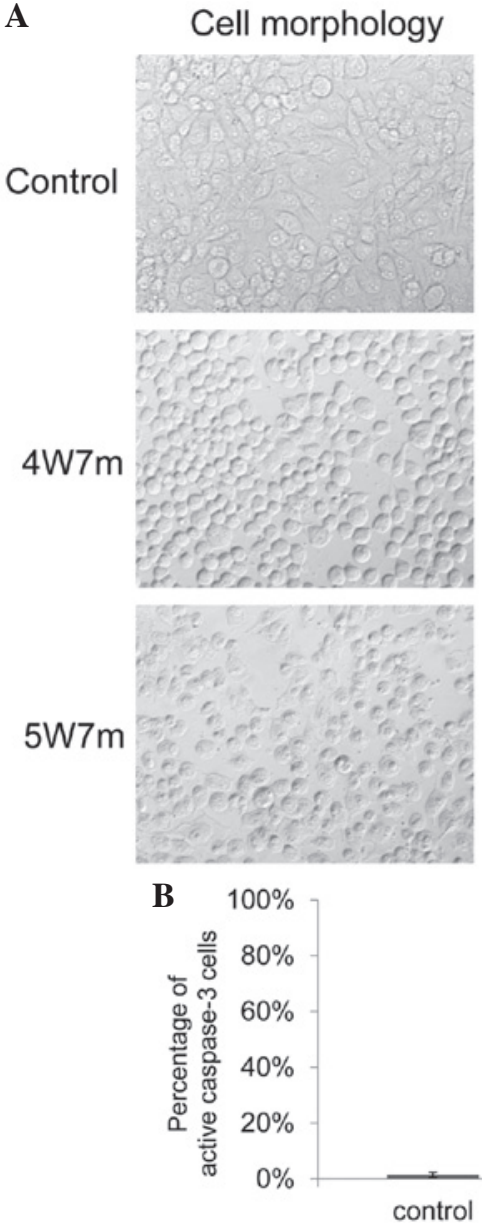

control
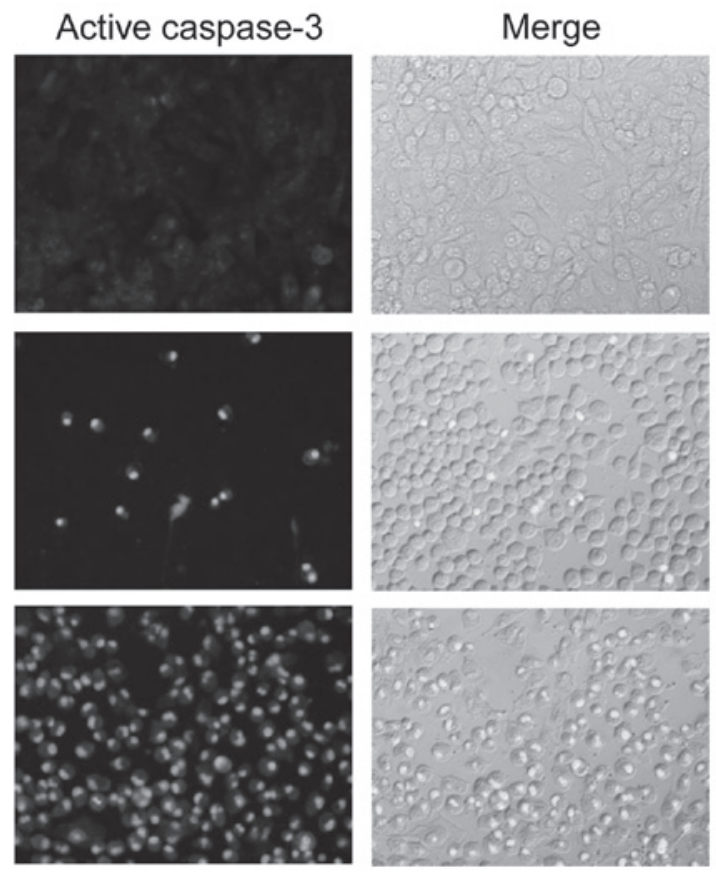

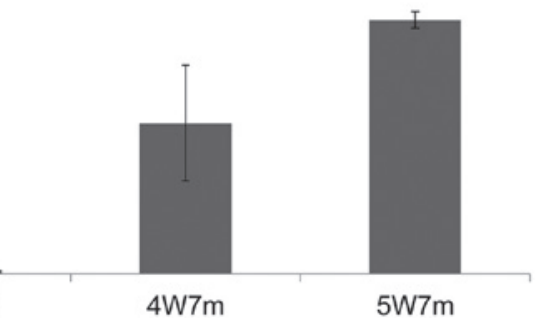

Figure 2. Near-infrared radiation induces caspase-3 activation.(A) KP4 cells cultured in 96-well plates were irradiated with a 915 nm laser at different powers and for various durations. Then, $2 \mathrm{~h}$ later, caspase-3 activation was evaluated in the cells. Representative pictures are presented. (B) The graph indicates the percentage of cells with active caspase- 3 . A total of 5 independent fields were selected for evaluation, and 3 independent experiments were performed. $4 \mathrm{~W} 7 \mathrm{~m}$, cells treated with a 4 -Watt laser for $7 \mathrm{~min} ; 5 \mathrm{~W} 7 \mathrm{~m}$, cells treated with a 5 -Watt laser for $7 \mathrm{~min}$.

using unpaired Student's t-tests. $\mathrm{P}<0.05$ was considered to indicate a statistically significant difference.

\section{Results}

Apoptosis in KP4 pancreatic cancer cells following NIR treatment. A 915-nm laser (Brother Industries) was used to automatically irradiate cells in 96-well plates for different durations and at varying powers. The KP4 pancreatic cancer cell line was used to examine whether irradiation with a 915-nm laser exerted an effect on cancer cells. The KP4 cells were irradiated for different durations and at different powers, and then $24 \mathrm{~h}$ later, the cells were subjected to the TUNEL assay to assess apoptosis (Fig. 1A). A limited number of apoptotic cells were observed following irradiation with a 3-Watt (W) laser; however, apoptotic cells were observed following an increase in the power of the laser and the duration of treatment. Almost $10 \%$ and $30 \%$ of the cells became apoptotic $24 \mathrm{~h}$ following irradiation with a $4 \mathrm{~W}$ laser for $7 \mathrm{~min}$ and a $5 \mathrm{~W}$ for $5 \mathrm{~min}$, respectively (Fig. 1B). Apoptosis was induced in almost $90 \%$ of KP4 cells following irradiation with a $5 \mathrm{~W}$ laser for $7 \mathrm{~min}$ (Fig. 1B).

To further confirm these results, the activation of caspase- 3 following irradiation was examined. Caspase- 3 is a member of the cysteine-aspartic acid protease family and is activated in the apoptotic cell by extrinsic (death ligand) and intrinsic (mitochondrial) pathways. Activation of caspase-3 was examined $2 \mathrm{~h}$ following irradiation (11). As demonstrated in Fig. 2A, irradiation induced activation of caspase-3 in a large proportion of the cells, as $\leq 5 \%$ of the non-irradiated cells were positive for caspase- 3 activation, compared with $\geq 50 \%$ of the cells irradiated with a $4 \mathrm{~W}$ laser for $7 \mathrm{~min}$. These results indicate that irradiation with a $915 \mathrm{~nm}$ laser promotes cellular apoptosis.

Apoptosis in MIA-PaCa2 and PK9 pancreatic cancer cells following NIR treatment. The effects of NIR treatment on additional pancreatic cancer cell lines, consisting of the MIA-PaCa2 and PK9 cell lines, were also evaluated. Notably, these cells demonstrated different sensitivity to irradiation (Fig. 3). Similarly to KP4 cells, apoptotic MIA-PaCa2 cells started to appear following irradiation with a $4-\mathrm{W}$ laser, and $\geq 10 \%$ of MIA-PaCa2 cells became apoptotic following $3 \mathrm{~min}$ of irradiation with a 5-W laser. Conversely, few apoptotic cells were observed following irradiation of PK9 cells with a 5-W laser for 3 min; however, there was a sudden increase in the number of apoptotic cells when PK9 cells were irradiated for $5 \mathrm{~min}$ with a $5-\mathrm{W}$ laser. These results indicate that the threshold for apoptosis induction using a 915-nm laser varies between different pancreatic cancer cell lines. 


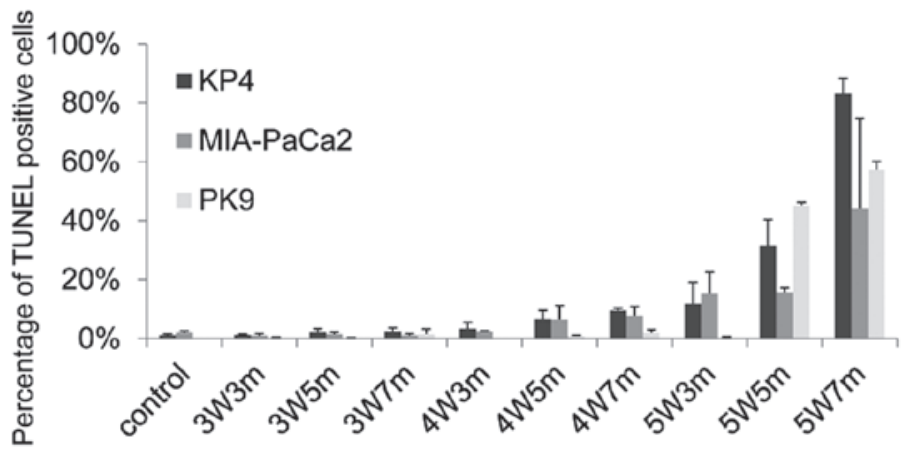

Figure 3. Near-infrared radiation promotes apoptosis of MIA-PaCa2 and PK9 cells. The graph presents the percentage of TUNEL positive cells. 3W3m, cells treated with a 3-Watt laser for $3 \mathrm{~min} ; 3 \mathrm{~W} 5 \mathrm{~m}$, cells treated with a 3-Watt laser for $5 \mathrm{~min} ; 3 \mathrm{~W} 7 \mathrm{~m}$, cells treated with a 3-Watt laser for $7 \mathrm{~min} ; 4 \mathrm{~W} 3 \mathrm{~m}$, cells treated with a 4-Watt laser for $3 \mathrm{~min} ; 4 \mathrm{~W} 5 \mathrm{~m}$, cells treated with a 4-Watt laser for $5 \mathrm{~min} ; 4 \mathrm{~W} 7 \mathrm{~m}$, cells treated with a 4 -Watt laser for $7 \mathrm{~min} ; 5 \mathrm{~W} 3 \mathrm{~m}$, cells treated with a 5-Watt laser for $3 \mathrm{~min} ; 5 \mathrm{~W} 5 \mathrm{~m}$, cells treated with a 5 -Watt laser for $5 \mathrm{~min} ; 5 \mathrm{~W} 7 \mathrm{~m}$, cells treated with a 5 -Watt laser for $7 \mathrm{~min}$.

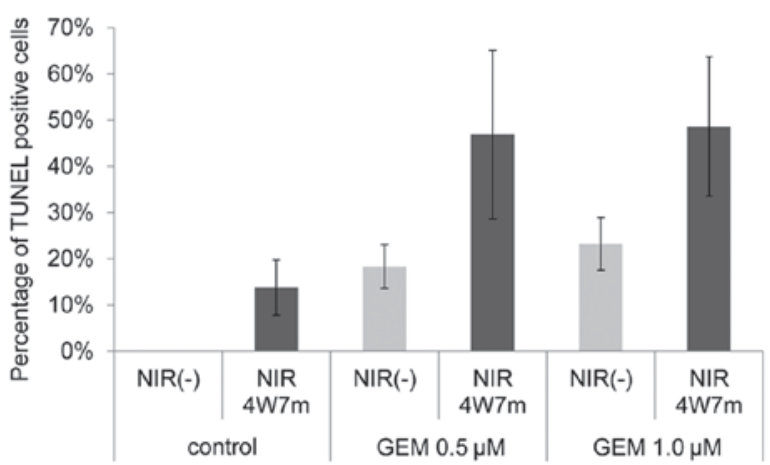

Figure 4. Combined treatment of NIR and GEM synergistically promotes apoptosis. The cells were treated with gemcitabine for $48 \mathrm{~h}$ and then irradiated with a 4 Watt $915 \mathrm{~nm}$ laser for $7 \mathrm{~min}$. After $24 \mathrm{~h}$, the cells were subjected to the TUNEL assay. NIR, near-infrared radiation; GEM, gemcitabine; 4W7m, cells treated with a 4-Watt laser for $7 \mathrm{~min}$. P $<0.05$ between NIR(-) and NIR4W7m groups.

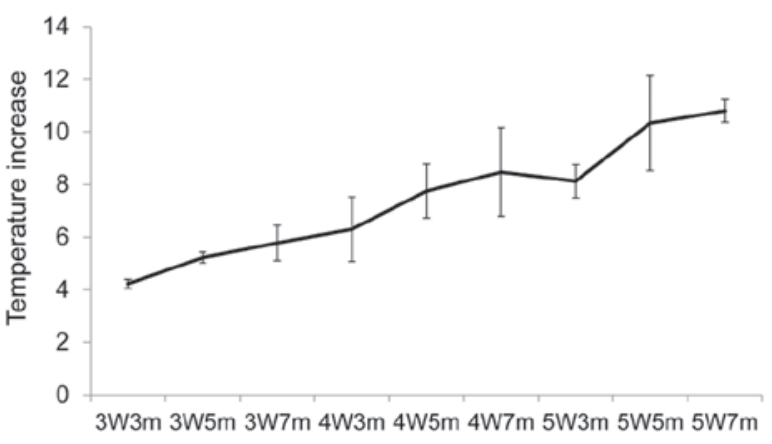

Figure 5. Temperature increases in the cell media following near-infrared irradiation. Temperature increases during irradiation were measured using a thermocouple. The graph demonstrates the increase in the temperature of the media during irradiation with the indicated duration and power. $3 \mathrm{~W} 3 \mathrm{~m}$, treated with a 3 -Watt laser for $3 \mathrm{~min} ; 3 \mathrm{~W} 5 \mathrm{~m}$, treated with a 3 -Watt laser for $5 \mathrm{~min} ; 3 \mathrm{~W} 7 \mathrm{~m}$, treated with a 3 -Watt laser for $7 \mathrm{~min} ; 4 \mathrm{~W} 3 \mathrm{~m}$, treated with a 4-Watt laser for $3 \mathrm{~min}$; $4 \mathrm{~W} 5 \mathrm{~m}$, treated with a 4 -Watt laser for $5 \mathrm{~min} ; 4 \mathrm{~W} 7 \mathrm{~m}$, treated with a 4 -Watt laser for $7 \mathrm{~min} ; 5 \mathrm{~W} 3 \mathrm{~m}$, treated with a 5 -Watt laser for $3 \mathrm{~min} ; 5 \mathrm{~W} 5 \mathrm{~m}$, treated with a 5 -Watt laser for $5 \mathrm{~min} ; 5 \mathrm{~W} 7 \mathrm{~m}$, treated with a 5-Watt laser for $7 \mathrm{~min}$

Evaluation of gemcitabine treatment in combination with NIR on KP4 pancreatic cancer cells. The present study evaluated whether the combination of an anticancer drug and NIR treatment exerted synergistic effects on KP4 pancreatic cancer cells. Gemcitabine is widely used for the treatment of pancreatic cancer. KP4 cells were treated with gemcitabine for $48 \mathrm{~h}$ and were then treated or not treated with a 915-nm laser of $4 \mathrm{~W}$ for $7 \mathrm{~min}$. The TUNEL assay was performed to evaluate the percentage of apoptotic cells $24 \mathrm{~h}$ following irradiation. As demonstrated in Fig. 4, the combination of gemcitabine and irradiation significantly increased the percentage of apoptotic cells compared with either treatment alone.

Exclusion of apoptosis induced by thermal energy. To exclude the possibility that the observed apoptosis was induced by thermal energy, the changes in temperature during irradiation were measured. Temperature increases were observed with each increase in power and duration (Fig. 5). An increase in temperature of $\sim 11^{\circ} \mathrm{C}$ was observed when the cells were irradiated with a $5-\mathrm{W}$ laser for $7 \mathrm{~min}$, which was the maximum power and duration used in the experiments. The cells were incubated at $25^{\circ} \mathrm{C}$ prior to the irradiation in all the experiments; therefore, it is unlikely that apoptosis was induced by the increase in temperature.

\section{Discussion}

In the present study, an automatic machine was used to irradiate pancreatic cancer cells with a 915-nm laser, and the effects of irradiation on pancreatic cancer cells were examined. A significant induction of apoptosis was observed with increasing power and duration of the irradiation. The irradiation laser induced temperature increases in the media; however, it appears that apoptosis was induced by irradiation and not thermal energy. Suppression of tumor cell proliferation requires an exposure for $\geq 60 \mathrm{~min}$ to high temperatures of $\sim 42^{\circ} \mathrm{C}$ (11). In the present study, the cells were incubated at $25^{\circ} \mathrm{C}$ prior to the irradiation. Therefore, a temperature increase of $\sim 10^{\circ} \mathrm{C}$ induced by the irradiation would not be sufficient to induce apoptosis of the cells. In accordance with the results of the present study, previous studies have demonstrated that NIR resulted in reduced cell proliferation and apoptosis in multiple cell lines, independent of the thermal energy $(10,12,13)$.

Low-energy non-ionizing radiation is known to affect numerous cellular activities by modulating electrochemical systems in cells, such as the modulation of mitochondrial 
signaling by NIR $(14,15)$. Cytochrome c oxidase is an enzyme that mediates the transfer of electrons from cytochrome $\mathrm{c}$ to molecular oxygen (16). The oxidase is a receptor of NIR and activates mitochondrial signaling in mammalian cells $(17,18)$. Differentiation of neural progenitor cells is also promoted by NIR. The radiation induces the production of ATP, which subsequently activates P2Y receptors for neurite outgrowth (19). Although the molecular mechanisms by which low-energy radiation affects various cellular activities are unclear, accumulating evidence indicates that NIR may be used in multiple clinical treatments (6-10). A number of previous studies have indicated the possible use of low-energy radiation for cancer treatment $(9,10)$. NIR elicited selective cytotoxic effects on tumor tissues $(20,21)$. Although the exact molecular mechanisms of how NIR exerts cytotoxic effects is not clear, a previous study indicated that double strand breaks in DNA are associated with apoptosis induction (22). NIR has been demonstrated to activate the DNA damage checkpoint pathway, resulting in cell cycle arrest in G2/M phase or the induction of apoptosis (23). These previous studies have indicated that NIR may be used for cancer treatment in combination with ionizing radiation or chemotherapeutic agents.

In the present study, pancreatic cancer cells were used to examine the effects of NIR. Pancreatic cancer is one of the most aggressive types of human cancer and is the leading cause of cancer-associated mortality $(24,25)$. Gemcitabine is currently the standard treatment for advanced or resected pancreatic cancer (26). However, since a large number of patients are resistant to gemcitabine treatment, this drug provides only modest survival benefits. In the present study, the combination of NIR and gemcitabine was more effective than either single treatment alone. Although it is not technically easy to directly irradiate pancreatic cancer, the development of such devices may be useful for the treatment of pancreatic cancer. Additional investigation into the development of NIR therapy may contribute to an improved prognosis for patients with cancer.

\section{Acknowledgements}

The authors would like to thank the members of the Division of Cancer Biology for their helpful discussions and technical assistance. This study was partially funded by a grant from the Ministry of Education, Culture, Sports, Science and Technology of Japan (grant nos. 2583114 and 23107010).

\section{References}

1. Chabner BA and Roberts TG Jr: Timeline: Chemotherapy and the war on cancer. Nat Rev Cancer 5: 65-72, 2005.

2. Salama JK, Chmura SJ, Mehta N, Yenice KM, Stadler WM, Vokes EE, Haraf DJ, Hellman S and Weichselbaum RR: An initial report of a radiation dose-escalation trial in patients with one to five sites of metastatic disease. Clin Cancer Res 14: 5255-5259, 2008.

3. Davis AJ and Chen DJ: DNA double strand break repair via non-homologous end-joining. Transl Cancer Res 2: 130-143, 2013.

4. Grossman N, Schneid N, Reuveni H, Halevy S and Lubart R: $780 \mathrm{~nm}$ low power diode laser irradiation stimulates proliferation of keratinocyte cultures: Involvement of reactive oxygen species. Lasers Surg Med 22: 212-218, 1998.
5. Karu T and Pyatibrat L: Gene expression under laser and light-emitting diodes radiation for modulation of cell adhesion: Possible applications for biotechnology. IUBMB Life 63: 747-753, 2011

6. Oron U, Yaakobi T, Oron A, Mordechovitz D, Shofti R, Hayam G, Dror U, Gepstein L, Wolf T, Haudenschild C and Haim SB: Low-energy laser irradiation reduces formation of scar tissue after myocardial infarction in rats and dogs. Circulation 103: 296-301, 2001

7. Oron U, Yaakobi T, Oron A, Hayam G, Gepstein L, Rubin O, Wolf $\mathrm{T}$ and Ben Haim S: Attenuation of infarct size in rats and dogs after myocardial infarction by low-energy laser irradiation.Lasers Surg Med 28: 204-211, 2001.

8. Shefer G, Barash I, Oron U and Halevy O: Low-energy laser irradiation enhances de novo protein synthesis via its effects on translation-regulatory proteins in skeletal muscle myoblasts. Biochim Biophys Acta 1593: 131-139, 2003.

9. Santana-Blank LA, Rodríguez-Santana E, Vargas F, Reyes H, Fernández-Andrade P, Rukos S and Santana-Rodríguez KE: Phase I trial of an infrared pulsed laser device in patients with advanced neoplasias. Clin Cancer Res 8: 3082-3091, 2002.

10. Tanaka Y, Matsuo K, Yuzuriha S, Yan H and Nakayama J: Non-thermal cytocidal effect of infrared irradiation on cultured cancer cells using specialized device. Cancer Sci 101: 1396-1402, 2010.

11. Shalini S, Dorstyn L, Dawar S and Kumar S: Old, new and emerging functions of caspases. Cell Death Differ 22: 526-539, 2015.

12. Tanaka Y, Matsuo K and Yuzuriha S: Near-infrared irradiation non-thermally affects subcutaneous adipocytes and bones. Eplasty 11: e12, 2011.

13. Tanaka Y, Matsuo K and Yuzuriha S: Near-infrared irradiation nonthermally induces long-lasting vasodilation by causing apoptosis of vascular smooth muscle cells. Eplasty 11: e22, 2011.

14. Schroeder P, Pohl C, Calles C, Marks C, Wild S and Krutmann J: Cellular response to infrared radiation involves retrograde mitochondrial signaling. Free Radic Biol Med 43: 128-135, 2007.

15. Karu TI: Mitochondrial signaling in mammalian cells activated by red and near-IR radiation. Photochem Photobiol 84: 1091-1099, 2008.

16. Karu TI: Multiple roles of cytochrome c oxidase in mammalian cells under action of red and IR-A radiation. IUBMB Life 62: 607-610, 2010.

17. Karu T: Primary and secondary mechanisms of action of visible to near-IR radiation on cells. J Photochem Photobiol B 49: 1-17, 1999.

18. Karu TI, Pyatibrat LV, Kolyakov SF and Afanasyeva NI: Absorption measurements of a cell monolayer relevant to phototherapy: Reduction of cytochrome c oxidase under near IR radiation. J Photochem Photobiol B 81: 98-106, 2005.

19. Anders JJ, Romanczyk TB, Ilev IK, Moges H, Longo L, Wu X and Waynant RW: Light supports neurite outgrowth of human neural progenitor cells in vitro: The role of $\mathrm{P} 2 \mathrm{Y}$ receptors IEEE J- Sel Top Quantum Electron 14: 118-125, 2008.

20. Karu T, Pyatibrat L and Kalendo G: Irradiation with He-Ne laser can influence the cytotoxic response of HeLa cells to ionizing radiation. Int J Radiat Biol 65: 691-697, 1994.

21. Dees C, Harkins J, Petersen MG, Fisher WG and Wachter EA: Treatment of murine cutaneous melanoma with near infrared light. Photochem Photobiol 75: 296-301, 2002.

22. Tirlapur UK and König K: Femtosecond near-infrared laser pulse induced strand breaks in mammalian cells. Cell Mol Biol (Noisy-le-grand) 47: OL131-OL134, 2001.

23. Tanaka Y, Tatewaki N, Nishida H, Eitsuka T, Ikekawa N and Nakayama J: Non-thermal DNA damage of cancer cells using near-infrared irradiation. Cancer Sci 103: 1467-1473, 2012.

24. Hidalgo M: Pancreatic cancer. N Engl J Med 362: 1605-1617, 2010.

25. Siegel R, Ma J, Zou Z and Jemal A: Cancer statistics, 2014. CA Cancer J Clin 64: 9-29, 2014.

26. Berlin J and Benson AB III: Chemotherapy: Gemcitabine remains the standard of care for pancreatic cancer. Nat Rev Clin Oncol 7: 135-137, 2010. 